\title{
DEVELOPMENT OF REAL-TIME INVESTIGATION TECHNIQUE FOR NONPOINT POLLUTION SOURCE DISTRIBUTION USING PROGRAMMING INTERFACE
}

\author{
Kwan Sik MIN ${ }^{1}$, Dong Ha LEE ${ }^{2}$, Tri Dev ACHARYA ${ }^{2}$ \\ ${ }^{1}$ Department of Civil Engineering, Hannam University, Daejeon, 34430, Republic of Korea \\ ${ }^{2}$ Department of Civil Engineering, Kangwon National University, Chuncheon, 24341, Republic of Korea
}

Received 02 July 2018; accepted 31 January 2019

\begin{abstract}
Currently both central and local governments that are aware of the importance of conserving rivers, are making continuous efforts to solve the problem of non-point pollution sources (NPS) flowing into rivers. This study established a reactive web service app with a mobile application, to accommodate the need for systematic and scientific investigation and management of NPS. The developed investigation and management techniques incorporate all the PC-based administrative features, thereby improving development efficiency. A prototype of mobile GIS platform for a survey, inspection, and input was proposed, in which data related to pollution source locations and attributes can be effectively collected, stored, updated, and adjusted. To demonstrate, we conducted a quantitative analysis of river pollution source using GPS and GIS to show further details of the framework, which provides geographic information required to develop management technique of NPS flowing into rivers and related parameters in the form of a map. Furthermore, based on the interpolated maps and various environmental factors, the prediction of NPS as well as other parameters can be done. The research will not only improve the efficiency of investigation and management of NPS but also contribute to establishing a management policy, which covers quick decision-making and reaction to inflow accidents.
\end{abstract}

Keywords: non-point pollution sources (NPS), reactive web service, geographic information (GI), mobile GIS, GPS, pollution source investigation and management technique.

\section{Introduction}

Industrialized and urbanized modern society has caused many environmental problems. In urban areas, river water pollution due to the point and non-point pollution sources is increasing every year (Zamparas \& Zacharias, 2014). Generally, the sources of pollution, which flow from the upper region or branches of a river, are automatically purified by being diluted in water, decomposed by aerobic bacteria, or precipitated at the river bottom. However, recently, in urban areas, there is a decrease in green space and an increase in concrete buildings and impervious asphalt pavements, resulting an increase in surface runoff and a decrease in soil absorption rate (McGrane, 2016; Hobbie et al., 2017). Under these conditions, during summer rains or downpour, the pollutants on the ground surface flow into rivers and tend to increase pollution loads significantly (Chen, Zhou, Pickett, Li, \& Han, 2016; Jung et al., 2016). Among the various pollution sources flowing into urban rivers, non-point sources (NPS) refer to the open storage and road surface drainage in a city. It is difficult to identify the discharge point and route of this pollution source, which runs throughout the city, during the summer downpour (Chen et al., 2016).

Efficient management of such NPS needs to be preceded by the investigation of both the pollution source and various causes of pollution, modelling path and forecasting pollution loads in different land-use environment (Min, 2014). In recent years, NPS studies are widely conducted but are mostly focused on the development of models in specific watersheds all around (Liu, Shen, Yan, \& Yang, 2018; Ouyang et al., 2017). Integration of Best Management Practices (BMP) to improve water quality has also been conducted (Fonseca, Boaventura, \& Vilar, 2018). However, Korea has conducted limited work in this field (Lee et al., 2010; Cho, T. Jang, J. R. Jang, \& Yoon, 2016; C. Lee, Kim, \& H. Lee, 2018).

Mutch (1998) suggested that with the consideration of the locations of the samples within a watershed can help

${ }^{*}$ Corresponding author. E-mail: geodesy@kangwon.ac.kr 
in the interpretation of nitrate data and could lead to the success of BMPs. Although lack of considering hydraulic and geographic conditions, in this case, has been found in the assessment, an inadequate number of random samples usually provides no more information than investigating site-specific pollution within an isolated region. It is difficult to reveal the essential characteristics of regional distribution of agriculture-derived pollution due to limited sampling density or lack of necessary hydraulic data. In a study done by Liu, Wu, and Zhang (2005), they found that nitrate- $\mathrm{N}$ concentration in the groundwater varied widely from place to place though relative uniform field managements were practised in the study area. The spatial variation could not be explained by the site-specific data, which suggested an unidentified mechanism plays an important role. These spatial variations can be easily visualized and understood in Geographical Information System (GIS) upon updates with adequate samples over time (Ramadas \& Samantaray, 2018).

In order to monitor and regulate the NPS in Korean urban areas, firstly the investigation of the causes of pollution for any area needs a complete Geographic Information (GI) that must be collected and analysed for various pollution sources. Utilizing the GI of pollution sources flowing into a river, the topographical map and properties of pollution sources can be organically combined through a retrieval system, which conducts various spatial analyses and meets user requests immediately. The convergence of various GI and IT in relation to urban pollution source investigation and data construction is crucial in analyzing the causes of pollution sources and their discharge areas for the investigation and management of river pollutants. The comprehensive and efficient management of urban pollution sources cannot be effective by applying only one method, and therefore, an adequate technical combination of multiple methods is required. Above all, institutional management needs to be ensured by strengthening or enacting relevant regulations or laws such as the Water
Quality Conservation Act (Ministry of Environment, 2006).

Besides, a GI system is necessary for developing river pollution management techniques in which every form of pollution source information is geographically available. Every aspect must be effectively visualized for its collection, storage, update, adjustment, and analysis. The introduction of a GIS system for pollution sources flowing into a river can combine topographical map and characteristic properties of pollution sources through a retrieval system that conducts various spatial analyses and meets user request immediately. In this way, the pollution sources can be efficiently managed. Shin, Kim, Chae, Kwon, and Lee (2002) developed a Graphic User Interface (GUI) system using Arc-View and Visual Basic at the circumstances based on the PC. The integrated GIS and Remote Sensing based system are directed to the need for more detailed information on watershed management. It was dependent on the propriety software and has been obsolete now.

This research demonstrates that the existing survey technique can be used to analyse NPS with a GIS system in order to develop a management technique for visualizing and managing urban river pollution. We selected a small area in which sampling points were pinpointed through aerial photographs, prepared a management method, and surveyed pollution sources according to land use around a river into which the sources flow. Figure 1 illustrates the process of establishing a technique for a pollutant management system.

In addition, information obtained from digital aerial photographs can be used to identify the location and route of pollution sources. This work only surveys a small sample of four at a river conflux for the analysis of pollution sources. The sampled points data can be used in various spatial analyses of pollution sources using a GIS-based method. Such merging of attributes of pollution source and GI is aimed at developing a technique for managing river pollution sources.

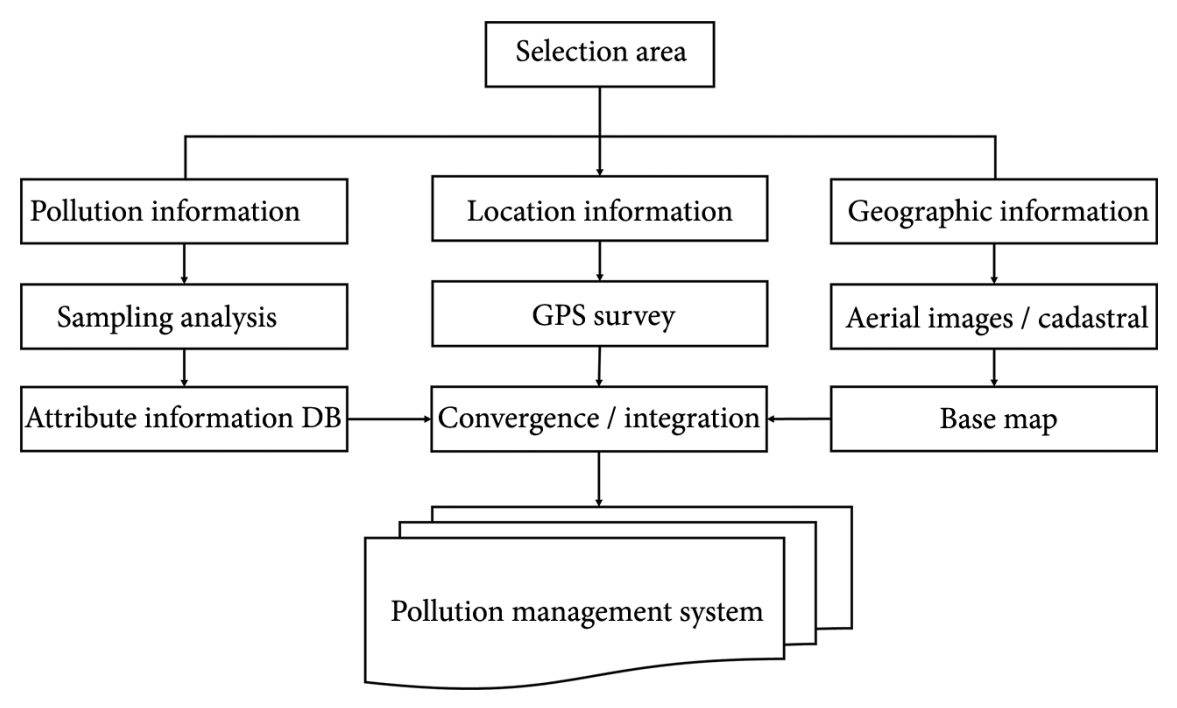

Figure 1. Process of developing a pollution management technique 
Table 1. Comparison between point and non-point pollution sources (Ministry of Environment, 2007)

\begin{tabular}{|l|l|l|}
\hline \multicolumn{1}{|c|}{ Type } & \multicolumn{1}{|c|}{ Point pollution source } & \multicolumn{1}{c|}{ Non-point pollution sources } \\
\hline Source & $\begin{array}{l}\text { Factory, domestic sewage, excreta treatment plant, } \\
\text { livestock farm }\end{array}$ & Ground, road, rice paddy, field, woodland, air pollutants \\
\hline $\begin{array}{l}\text { Charac- } \\
\text { teristics }\end{array}$ & $\begin{array}{l}\text { - Artificial } \\
\text { - Discharge point can be clearly identified } \\
\text { - Discharge is concentrated at one site (mainly } \\
\text { treatment plants) through pipes. } \\
\text { - Slightly affected by natural factors, so the annual } \\
\text { quantity of effluence is constant } \\
\text { - Easy to collect and high treatment efficiency }\end{array}$ & $\begin{array}{l}\text { - Artificial and natural } \\
\text { - Discharge point cannot be clearly identified } \\
\text { - Discharge over a large area due to dilution and diffusion } \\
\text { - Drastic change in quantity of effluence affected by natural } \\
\text { factors like rainfall makes estimation difficult } \\
\text { - Collection is difficult and treatment efficiency is not } \\
\text { constant } \\
\text { - Effluence standard has not been established on an } \\
\text { institutional basis }\end{array}$ \\
\hline Type & Point pollution source & Non-point pollution sources \\
\hline
\end{tabular}

Table 2. Design item and orientation for non-point pollution sources survey and management

\begin{tabular}{|l|l|l|}
\hline \multicolumn{1}{|c|}{ Item } & \multicolumn{1}{|c|}{ Design orientation } & Note \\
\hline Application of user friendly UI/UX & Screen design by constructing user friendly UI/UX & User friendliness \\
\hline Personal information protection & $\begin{array}{l}\text { Application of smart phone information protection program for } \\
\text { personal information protection }\end{array}$ & User friendliness \\
\hline Multi-OS support & Mobile multi-OS support for Android and iOS & User friendliness \\
\hline Simplified function & $\begin{array}{l}\text { Realization of simplified functions optimized for mobile device } \\
\text { screen }\end{array}$ & User friendliness \\
\hline $\begin{array}{l}\text { Real time synchronization with cloud } \\
\text { service server }\end{array}$ & $\begin{array}{l}\text { Minimization of transmission errors by real time synchronization } \\
\text { between smart phone and cloud service server }\end{array}$ & System optimization \\
\hline
\end{tabular}

\section{Non-point pollution sources and survey outline}

\subsection{Non-point pollution sources}

Point and non-point pollution sources are two types of pollution sources flowing into urban rivers and soil. As point pollution sources are discharged from urban plants, domestic sewage, excreta treatment plants, and livestock farms, these sources of pollution are clearly limited to specific areas. Point pollution sources are discharged mostly through sewer pipes for treatment facilities and the quantity of effluents is affected little by natural factors, thereby showing a constant annual quantity. Besides, such sources are easily collected, and the treatment efficiency is high. On the other hand, NPS is discharged mainly from urban ground, road, air pollutants, paddy fields, and woodland. Thus, in this case, the discharge points are not clear and are difficult to identify. Such pollution sources are often discharged over a large area by being diluted and diffused. As the quantity of effluents increases greatly during summer rains and downpour, they are not easy to estimate and quantify. Therefore, it is difficult to collect NPS, and treatment efficiency is not constant. Table 1 presents the comparison between sources and characteristics of point and non-point pollution sources classified by the Korean Ministry of Environment.
Table 3. Construction and explanation of survey and management functions for non-point pollution sources

\begin{tabular}{|l|l|}
\hline \multicolumn{1}{|c|}{ Function } & \multicolumn{1}{c|}{ Explanation } \\
\hline Main menu & $\begin{array}{l}\text { Project setting, registration of image } \\
\text { information, object attribute, registration } \\
\text { of location, map, field list, current location } \\
\text { setting, environment setting, alignment } \\
\text { mode, display coordinate, user guide, etc. }\end{array}$ \\
\hline Mode setting & Survey mode setting \\
\hline Map view & $\begin{array}{l}\text { Current survey point, and projection map } \\
\text { are shown }\end{array}$ \\
\hline Edit & Survey information is edited \\
\hline Status & $\begin{array}{l}\text { Normal status of the equipment currently in } \\
\text { use is displayed }\end{array}$ \\
\hline $\begin{array}{l}\text { Data } \\
\text { export }\end{array}$ & $\begin{array}{l}\text { Surveyed data is exported to a service server } \\
\text { through smart phones }\end{array}$ \\
\hline
\end{tabular}

\subsection{Basic plan of realizing the survey technique for non-point pollution sources}

This research attempts to construct a Database (DB) of attribute information and develop a mobile app for field survey based on GI of pollution sources flowing into urban rivers. Specifically, on the basis of a base map constructed by combining the attribute information of pollution sources and multidimensional geospatial data, a 
pollution source management technique was developed for performing real-time field survey using a mobile device and GPS location information. This research also includes the construction of mobile GIS platform, in which the results of field survey and inspection are input, and the pollution source information stored in a smart phone is transmitted and stored in a DB server by means of field synchronization.

To be specific, field photographs and attribute information are prepared by mobile devices and transmitted to a cloud server. Such a real-time sharing and utilization technique for field survey information can manage the attribute information of an object as a single data, and the data management technique that connects the mobilebased survey information with a cloud server enables data to be updated and shared in real-time.

This research focuses on a mobile-based application for the field survey of NPS and intends to realize the convergence between the attribute of pollution in the GI environment. The GIS-based survey technique of environmental pollution source is directly enabled in cloud servers after field update. In other words, the prototype of a mobile GIS platform for a survey, inspection, and input is proposed, in which data on pollution locations and its attributes can be effectively collected, stored, updated, and adjusted. The explanation of the design items and the menu interface of the developed application interface are explained in Table 2 and Table 3 respectively.

\subsection{Selection of study area}

For the survey of NPS flowing into urban rivers, this research acquired accurate locations of sampling points from GPS measurement, overlaying geospatial and attributes information of surveys, analysis of the pollution sources, and thus established efficient benchmarks for river pollution management technique.

In the process, the first step is to conduct GPS measurement of the location of each source and to survey the attribute of the source in an object area. Then, the samples are collected and analysed to identify background concentration. The analysed attribute information of NPS constitutes a database. In addition, GI needs to be established based on spatial information using aerial images, digital maps, and a series of cadastral maps. And such GI can be combined with the location and attribute information of pollution attributes distribution.

In order to track and manage NPS flowing into an urban river, a small prototype study area was selected in which GPS measurement and sampling of the NPS with river water qualities that are pollution indicators were conducted. The study area was in Daejeon metropolitan city. Figure 2 shows the location of study areas in satellite image along with surveying photographs. It is around the river confluence of Daejoencheon and Yudeungcheon. Their coordinates are shown in Table 4.

Table 4. Coordinates of the sampling points for NPS

\begin{tabular}{|c|c|c|c|}
\hline ID & $\mathrm{X}$ & $\mathrm{Y}$ & $\mathrm{H}(\mathrm{m})$ \\
\hline $\mathrm{A}$ & 36.335348 & 127.42277 & 48.525 \\
\hline $\mathrm{B}$ & 36.338108 & 127.42026 & 44.318 \\
\hline $\mathrm{C}$ & 36.349077 & 127.402597 & 43.339 \\
\hline $\mathrm{D}$ & 36.353321 & 127.403641 & 36.991 \\
\hline
\end{tabular}

The samples were collected at Samseon-gyo (a) and Mumyeong-gyo (b), which are the confluences of Daejeoncheon and its tributary, and at Samcheon-gyo (c) and Samcheon bicycle road (d), where Yudeungcheon meets Daejeoncheon.
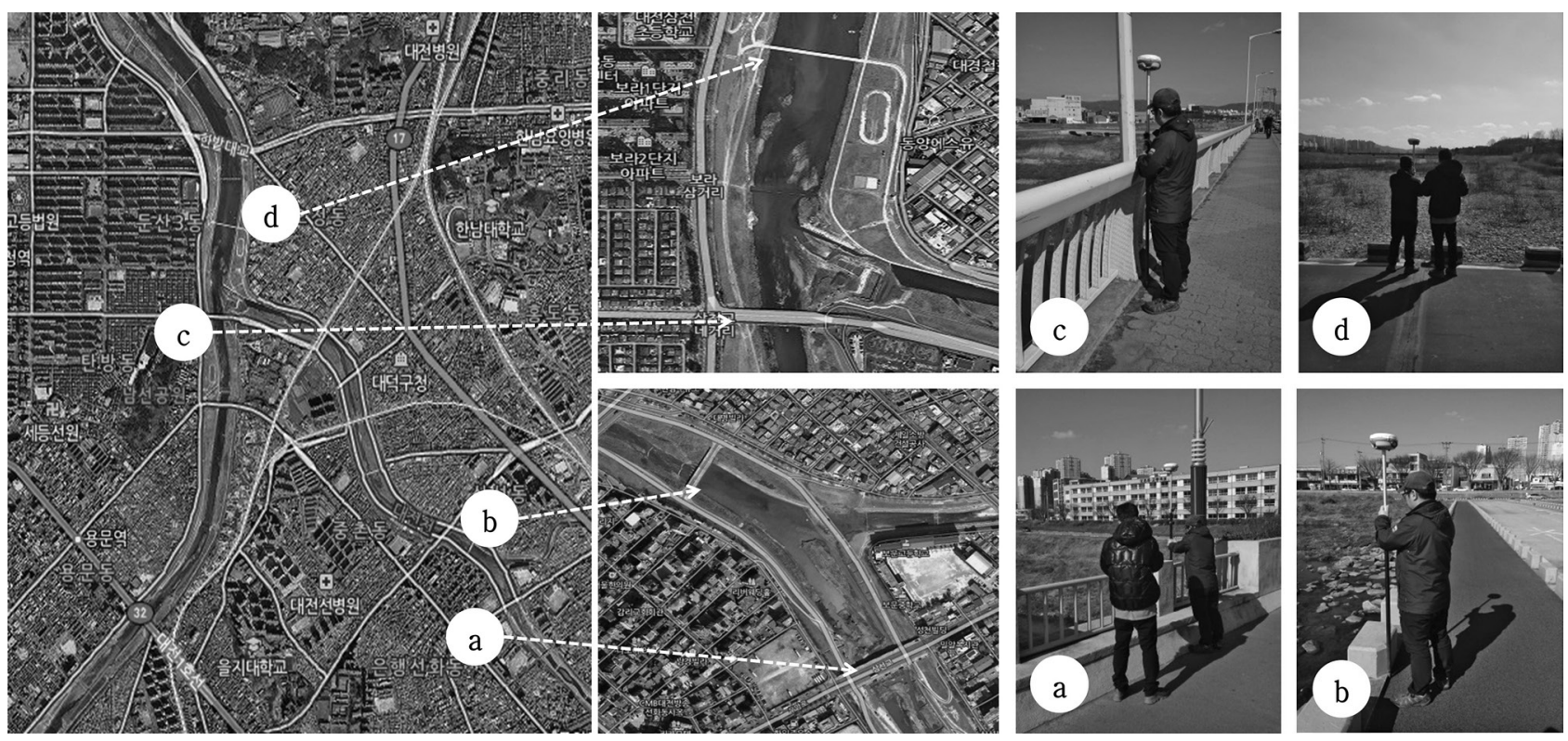

Figure 2. The study area in satellite image along with digital image while surveying (a) Samseon-gyo, (b) Muyeong-gyo, (c) Sam-cheon-gyo, (d) Samcheon-bicycle road 
Table 5. Water quality parameters at four sites for one instance of sample

\begin{tabular}{|c|c|c|c|c|c|c|c|c|c|}
\hline ID & $\begin{array}{c}\mathrm{T} \\
\left({ }^{\circ} \mathrm{C}\right)\end{array}$ & $\begin{array}{c}\mathrm{DO} \\
(\mathrm{mg} / \mathrm{L})\end{array}$ & $\begin{array}{c}\mathrm{EC} \\
(\mu \mathrm{s} / \mathrm{cm})\end{array}$ & $\mathrm{pH}$ & $\begin{array}{c}\mathrm{BOD} \\
(\mathrm{mg} / \mathrm{L})\end{array}$ & $\begin{array}{c}\mathrm{COD} \\
(\mathrm{mg} / \mathrm{L})\end{array}$ & $\begin{array}{c}\mathrm{TN} \\
(\mathrm{mg} / \mathrm{L})\end{array}$ & $\begin{array}{c}\mathrm{TP} \\
(\mathrm{mg} / \mathrm{L})\end{array}$ & $\begin{array}{c}\mathrm{SS} \\
(\mathrm{mg} / \mathrm{L})\end{array}$ \\
\hline $\mathrm{A}$ & 0.5 & 11.63 & 562 & 8.21 & 2.02 & 6.74 & 10.51 & 0.27 & 18.3 \\
\hline $\mathrm{B}$ & 0.5 & 11.38 & 606 & 8.48 & 1.67 & 6.74 & 9.02 & 0.16 & 19.11 \\
\hline $\mathrm{C}$ & 2 & 12.28 & 626 & 8.33 & 1.67 & 16.09 & 8.49 & 0.28 & 20.17 \\
\hline $\mathrm{D}$ & 2 & 11.98 & 361 & 8.29 & 1.46 & 13.71 & 7.6 & 0.08 & 17.12 \\
\hline
\end{tabular}

From all the sampled sited, water quality parameters were tested and recorded. Nine parameters namely Temperature (T), Dissolved Oxygen (DO), Electrical Conductivity $(\mu \mathrm{s} / \mathrm{cm}), \mathrm{pH}$ level, Biological Oxygen Demand (BOD), Chemical Oxygen Demand (COD), Dissolved Total Nitrogen (TN), Dissolved Total Phosphorus (TP) and Suspended Solids (SS) were tested and added by the user interface as a data base. Most of these are a major indicator of pollution in a watershed such as nitrogen and phosphorous represents various pollutant sources produced from agricultural areas, forests and impervious cover. Table 5 shows the measured water quality attributes measured at the site for one instance sampled water.

\section{Development of survey technique for non-point pollution sources}

In the design stage of the survey and the creation of $\mathrm{DB}$ for NPS in urban areas, the DB of the pollution sources is created by investigating the locations and attributes of each source and the field survey system based on smart phone and mobile device is designed. The method aims to maximize the efficiency of the survey and the management of the NPS.
In the construction stage, based on the GI-related survey technique that was developed, mobile devices are used to construct the field survey DB by computerizing the NPS data of urban areas, measuring GPS-based locations, and utilizing smart phone applications.

The field survey of pollution sources is a real-time field survey in which the existing relevant documents are computerized, attribute DB is constructed, a field survey plan is prepared based on map survey and GI, and mobile devices and GPS information are utilized for a real-time survey. Besides, the data about pollution discharge companies includes documents related to the installation and licensing of wastewater facilities, the installation of wastewater discharge facilities, the installation of NPS, and the installation and management of other water pollution sources. The pollution source information collected, registered, and stored by a smart phone in the real-time field survey is transmitted to the DB server by means of field synchronization. In addition, the field survey technique involves the GIS-based real-time field input of location and attributes information using smart phone, mobile PC and GPS. The detailed components of the technique include information registration, input editing of registered information, the expression on a
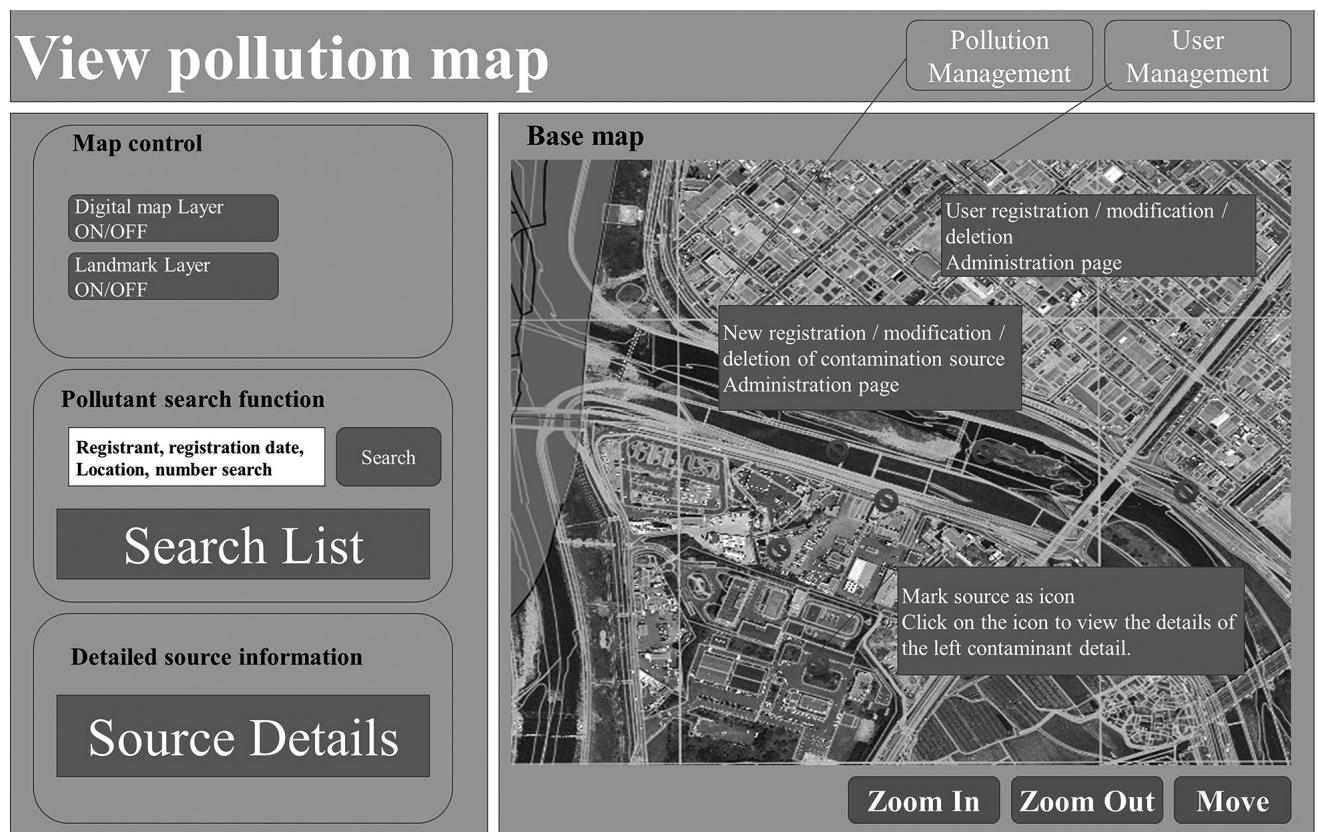

Figure 3. User interface for the search and view of pollution map 
map, management of registered information list, user management, and user group management. Anyone can easily register and use field image, attribute information and location information (Figure 3 for a user and Figure 4 for admin). The field input process includes inputting the GPS location information, inputting and modifying the survey information of pollution source, synchronizing registered information of the pollution source, and storing the information in DB server.

The prototype survey technique for NPS includes the construction of a base map for the pollution source survey based on the overlaying of attribute data and multidimensional GI as shown in Figure 5. The construction method utilizes either Naver or Daum satellite image service on an

\section{Pollution registration View Map $\left.\begin{array}{c}\text { Pollution } \\ \text { Management }\end{array}\right] \begin{gathered}\text { User } \\ \text { Management }\end{gathered}$}

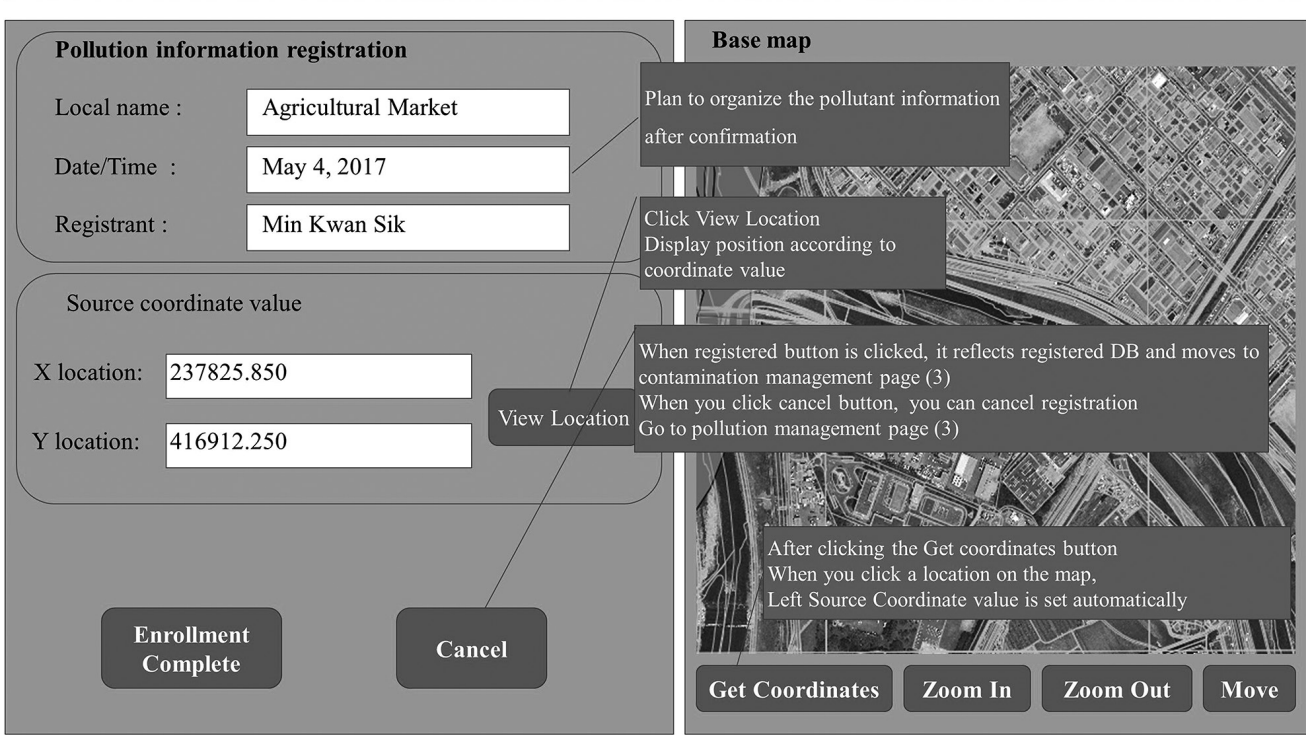

Figure 4. Administrative interface for pollution registration
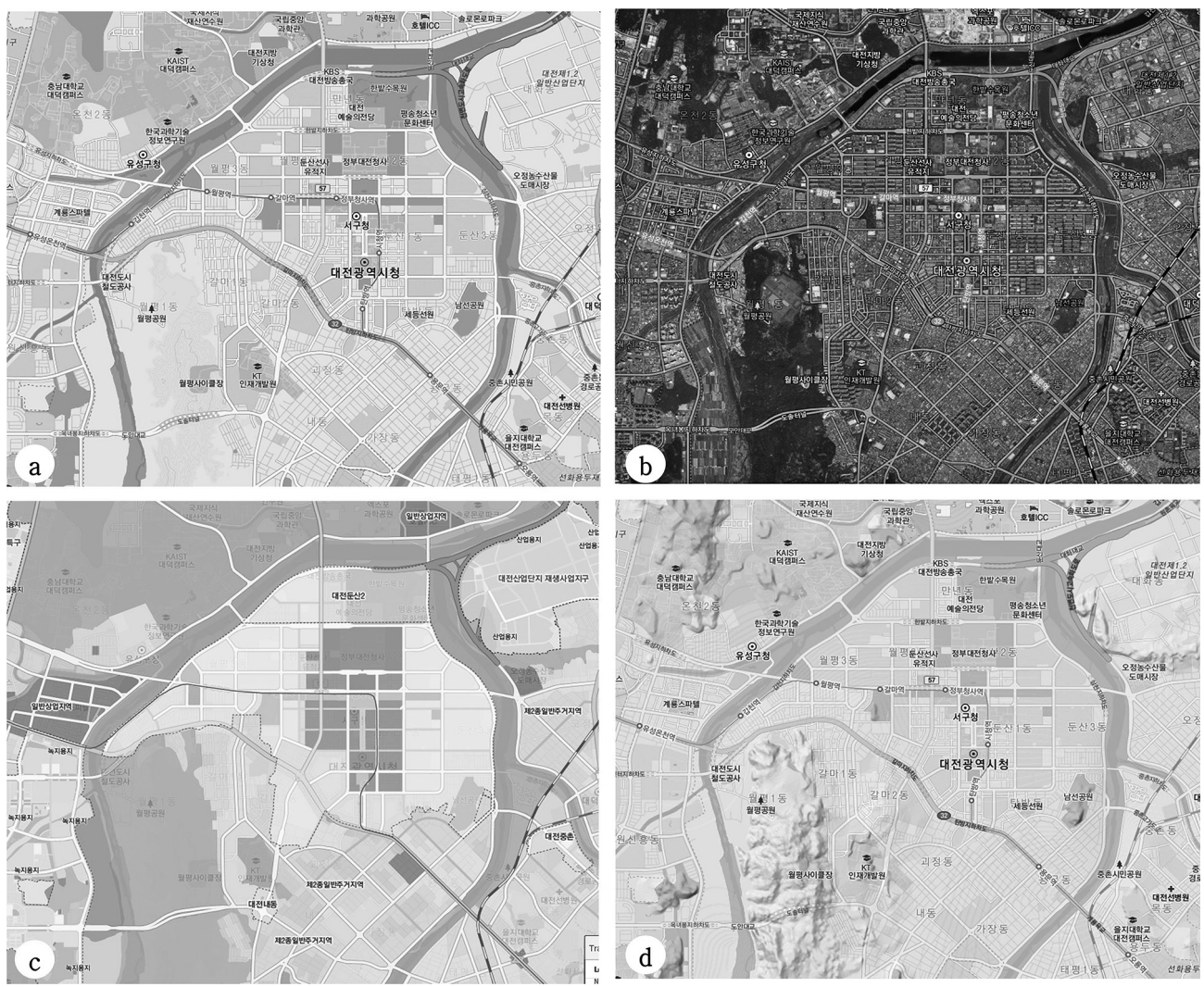

Figure 5. The resulted point locations or raster overlay of the real-time pollution attributes can be overlaid over four different maps of study area (a) vector map, (b) satellite view, (c) land use map and (d) terrain map 


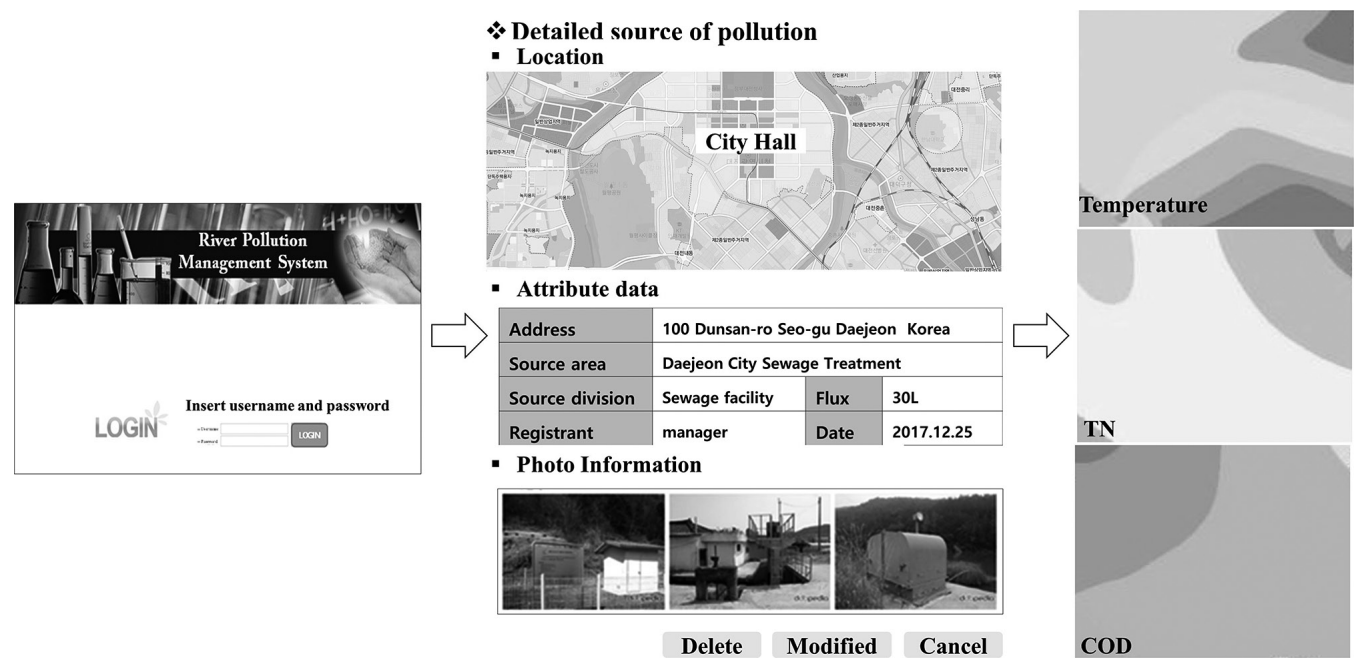

Figure 6. The web based reactive pollution management system showing the login interface, then single point details and attribute raster overlay in Daum satellite view map

open API basis or uses blended base maps of aerial images and series of cadastral maps. As a result, in the web interface, after login, the point interface can be visualized as shown in Figure 6. After the login by the user, the user can select each sampled point in the map layer for more details and can visualize the raster layer based on the sampled values over the satellite/vector maps.

\section{Development of real-time pollution mapping and management system}

In order to manage the river and monitor NPS pollution distributions systematically and scientifically that can help to improve the efficiency of water management, a river pollution management system was developed by introducing a GI system (Figure 7). The system includes every type of possible pollution attribute information, which is referenced geographically, which are effectively collected, analyzed, stored, and updated. In the survey stage of the pollution source, GIS-based image information and mobile-based attribute information using GPS location information are updated in real-time. In the stage of constructing the pollution source database, not only the field survey of pollution source but also registered information concerning water pollution discharge companies, oil, livestock farms, muddy water, floating matter, and basic environmental facilities are included to construct the DB based on the real-time sensors installed in bridges and nearby water drainages. On it is real-time sensing or manual sampling and input using a mobile device, the water quality parameters instantly update the database real-time. The constructed DB is integrated with GI so that the pollution distribution of individual areas could be managed in realtime by clicking the location information of the source. In the work, the integration of GI sets a foundation to track the route of the pollution source.

The concept of river pollution mapping and management system consists of two categories: internal and external. External categories are the user group with their mobile devices. These devices can be used to input data from field observation (Figure 4) with photographs as shown in Figure 6. Similarly, the internal categories are the administrator who manages the system and the server with different hardware and software. These two categories are connected by the internet. The system can take advantage of the recent advancement in hardware and networking technology such as cheap servers, multiple mobile devices and faster internet technology. Also, it can be built with the help of available wide option of open source programming and computing tools from the community.

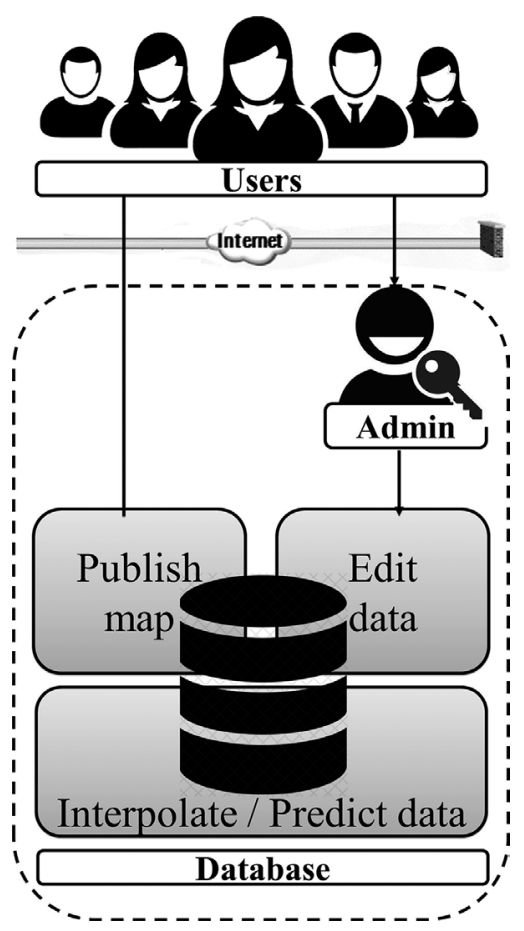

Figure 7. GIS framework of real-time pollution mapping and management system 


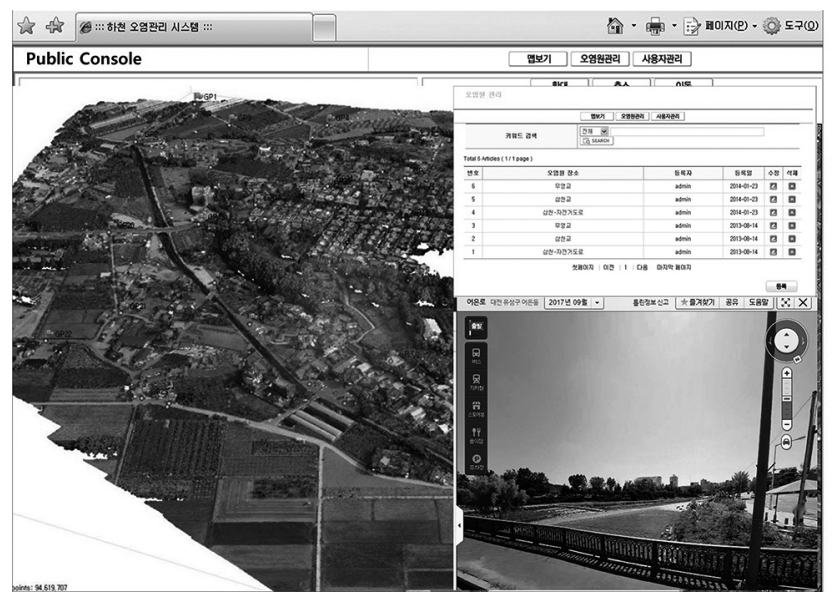

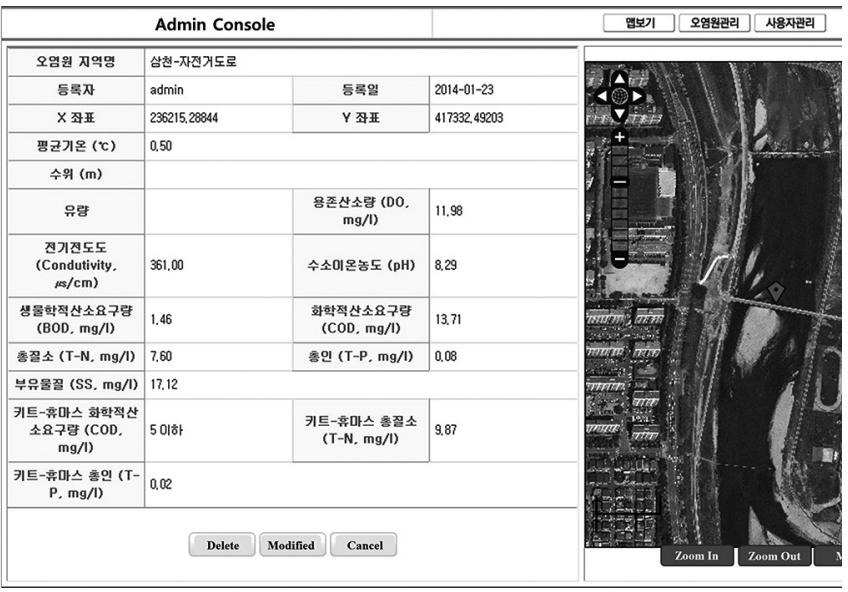

Figure 8. Webpage of pollution management system for public and admin with high-resolution UAV images, road view and reports

Users can interact with the system in two ways: first providing the input data such as location and photographs of any pollution-related evidence. Once the user creates authenticated account he/she can input data through the interface Figure 4. After the entry admin will check and determine the reality of the input. If approved, the data will be added to the system database. Only admin will have the right to edit and manipulate the entry points with necessary indicators.

Based on input data points, the GI system can either interpolate to produce the maps on the areas or use the modern machine learning techniques to predict the missing values in user entry or query points. As the system can use additional high-resolution satellite/UAV images along with other additional parameters, machine learning methods can be used to train and develop a model for the given watershed for prediction. Predicted values can be later verified using field measurements at a suitable time. The user can also query and view the desired point areas for the environmental parameters and photographs as shown in Figure 6 and Figure 8. Similarly, there will be also the availability of the interpolated maps to observe and analyse the overall scenario in the watershed.

The main feature of the work, NPS pollution management technique, is the integration of quantitative and spatial information in the analysis of the NPS in a river passing through an urban area. The geo-referenced NPS attributes distributions overlapped with digital aerial images could be used to track the origin and visualization of moving path that is important for the tracking of the NPS. Here the efficiency of NPS management takes full advantage of the integration of the NPS attributes and GI. Consequently, when a river pollution accident occurs, information can be provided for decision-making and reaction in real-time with sensors. This process can be taken as a guide for establishing the foundation of river management for authorities and local governments.

\section{Conclusions}

This research has developed an efficient management technique combining the NPS attribute and GI for river pollution by using spatial distribution of NPS flowing into an urban area. More specifically, a prototype of a mobile GIS platform for a survey, inspection, and input was proposed in which data on pollution source locations and attributes can be effectively collected, stored, updated, and adjusted. The mobile-based platform can update the database based in the cloud in real-time.

1. The pollution management technique, which is proposed in this research, will create the foundations for managing point and NPS, which have emerged as the major sources of urban river pollution, and establish a comprehensive measure to reduce the pollution.

2. The uses of GIS system enabled the spatial analysis of the NPS with geographic layers such as aerial image and cadastral information, thereby providing a foundation for the efficient management of river pollution sources.

3. The pollution management system is based on two categories: internal maintained by admin and external for the users. Users can input, query and view pollution for certain points or whole interpolated maps for a specific parameter overlapped over available maps and images.

4. The water quality can be efficiently handled through systematic and scientific maintenance of river pollution sources. Besides, when various types of river pollution accidents occur, basic information can be provided for quick decision-making and reaction.

In this way, a foundation has been established for both the central and local governments to analyse the risk factors of pollution source discharge and to carry out river maintenance works. 


\section{Acknowledgements}

This work was supported by the National Research Foundation of Korea (NRF) grant funded by the Korea government (MSIT) (No. NRF-2018R1A2B6009363).

\section{References}

Chen, X., Zhou, W., Pickett, S. T. A., Li, W., \& Han, L. (2016). Spatial-temporal variations of water quality and its relationship to land use and land cover in Beijing, China. International Journal of Environmental Research and Public Health, 13(5), 449. https://doi.org/10.3390/ijerph13050449

Chen, Y., Zhao, K., Wu, Y., Gao, S., Cao, W., Bo, Y., Shang, Z., Wu, J., \& Zhou, F. (2016). Spatio-temporal patterns and source identification of water pollution in Lake Taihu (China). Water, 8(3), 86. https://doi.org/10.3390/w8030086

Cho, M., Jang, T., Jang, J. R., \& Yoon, C. G. (2016). Development of agricultural non-point source pollution reduction measures in Korea. Irrigation and Drainage, 65(S1), 94-101. https://doi.org/10.1002/ird.1993

Fonseca, A., Boaventura, R. A., \& Vilar, V. J. (2018). Integrating water quality responses to best management practices in Portugal. Environmental Science and Pollution Research, 25(2), 1587-1596. https://doi.org/10.1007/s11356-017-0610-1

Hobbie, S. E., Finlay, J. C., Janke, B. D., Nidzgorski, D. A., Millet, D. B., \& Baker, L. A. (2017). Contrasting nitrogen and phosphorus budgets in urban watersheds and implications for managing urban water pollution. Proceedings of the National Academy of Sciences, 114(16), 4177-4182. https://doi.org/10.1073/pnas.1618536114

Jung, Y., Yeo, K., Oh, J., Lee, S., Park, J., \& Song, C. G. (2016). The economic effect of green roofs on non-point pollutant sources management using the replacement cost approach. KSCE Journal of Civil Engineering, 20(7), 3031-3044. https://doi.org/10.1007/s12205-016-0370-3

Lee, M., Park, G., Park, M., Park, J., Lee, J., \& Kim, S. (2010). Evaluation of non-point source pollution reduction by applying best management practices using a SWAT model and QuickBird high resolution satellite imagery. Journal of Environmental Sciences, 22(6), 826-833 (in Korean). https://doi.org/10.1016/S1001-0742(09)60184-4

Lee, C., Kim, K., \& Lee, H. (2018). GIS based optimal impervious surface map generation using various spatial data for urban nonpoint source management. Journal of Environmental Management, 206, 587-601.

https://doi.org/10.1016/j.jenvman.2017.10.076
Liu, J., Shen, Z., Yan, T., \& Yang, Y. (2018). Source identification and impact of landscape pattern on riverine nitrogen pollution in a typical urbanized watershed, Beijing, China. Science of the Total Environment, 628, 1296-1307. https://doi.org/10.1016/j.scitotenv.2018.02.161

Liu, G. D., Wu, W. L., \& Zhang, J. (2005). Regional differentiation of non-point source pollution of agriculture-derived nitrate nitrogen in groundwater in northern China. Agriculture, Ecosystems \& Environment, 107(2), 211-220. https://doi.org/10.1016/j.agee.2004.11.010

McGrane, S. J. (2016). Impacts of urbanisation on hydrological and water quality dynamics, and urban water management: a review. Hydrological Sciences Journal, 61(13), 2295-2311. https://doi.org/10.1080/02626667.2015.1128084

Min, K. S. (2014). A Study on the construction of pollution management system with influx the urban stream. Journal of Korea Spatial Information Society, 22(2), 45-52 (in Korean). https://doi.org/10.12672/ksis.2014.22.2.045

Ministry of Environment. (2007). Official testing method with respect to water pollution process (Ministry of Environment Notice No. 2007-147). Korea.

Ministry of Environment. (2006). Water environmental management master plan. Korea.

Mutch, J. (1998). The hydrologic cycle and water movement, Nitrate-agricultural sources and fate in the environmentperspectives and direction. In Proceedings of the workshop, Eastern Canada Soil and Water Conservation Centre, Charlottetown (pp. 3-7). Canada.

Ouyang, W., Gao, X., Wei, P., Gao, B., Lin, C., \& Hao, F. (2017). A review of diffuse pollution modeling and associated implications for watershed management in China. Journal of Soils and Sediments, 17(6), 1527-1536. https://doi.org/10.1007/s11368-017-1688-2

Ramadas, M., \& Samantaray, A. K. (2018). Applications of remote sensing and GIS in water quality monitoring and remediation: a state-of-the-art review. In S. Bhattacharya, A. B. Gupta, A. Gupta, \& A. Pandey (Eds.), Water remediation (pp. 225-246). Singapore: Springer. https://doi.org/10.1007/978-981-10-7551-3_13

Shin, S. C., Kim, S. J., Chae, H. S., Kwon, G. R., \& Lee, Y. A. (2002). Development of management system for a drainage basin using spatial information. Journal of the Korean Association of Geographic Information Studies, 5(3), 33-44 (in Korean).

Zamparas, M., \& Zacharias, I. (2014). Restoration of eutrophic freshwater by managing internal nutrient loads. A review. Science of the Total Environment, 496, 551-562. https://doi.org/10.1016/j.scitotenv.2014.07.076 